Supplement of Saf. Nucl. Waste Disposal, 1, 71-72, 2021

https://doi.org/10.5194/sand-1-71-2021-supplement

(C) Author(s) 2021. CC BY 4.0 License.

(c) (i)

Supplement of

\title{
An Open-Access Stress Magnitude Database for Germany
}

Sophia Morawietz et al.

Correspondence to: Sophia Morawietz (sophia.morawietz@gfz-potsdam.de)

The copyright of individual parts of the supplement might differ from the article licence. 
GF Z

Helmholtz-Zentrum P O T S A M
An Open-Access Stress Magnitude Database for Germany

\section{Data-driven geomechanics for the best possible repository}

S. Morawietz ${ }^{1,2}$, M. Ziegler ${ }^{1}, K$. Reiter ${ }^{3}$, the SpannEnD Project Team ${ }^{1,3,4}$
Spann EnD

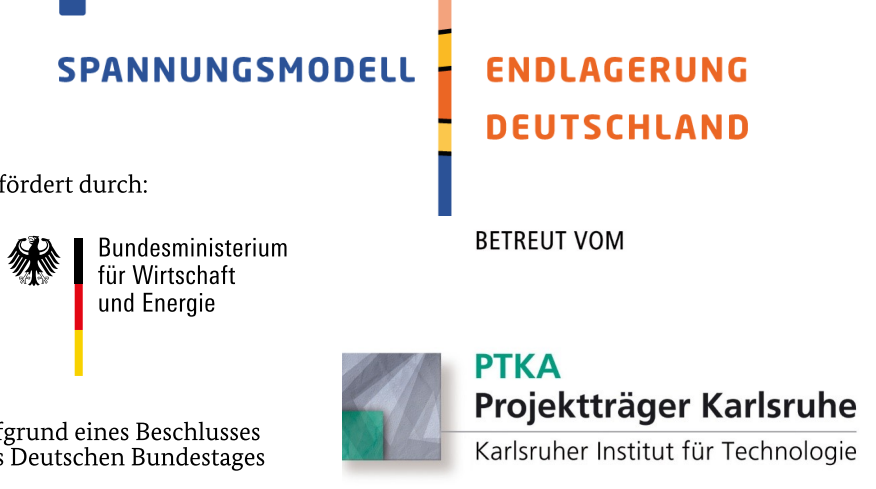

1. Helmholtz Centre Potsdam, GFZ German Research Centre for Geosciences, Germany

2. Institute of Applied Geosciences, Technical University Berlin, Germany;

3. Institute of Applied Geosciences, Technical University Darmstadt, Germany;
4. Institute of Applied Geosciences, Karlsruhe Institute of Technology, Germany.

\section{The impact of rock stresses on deep geological repositories}

The crustal stress field plays a major role in the characterization of a deep geological repository for nuclear waste. It influences factors such as - the excavation zone in the vicinity of the underground structures the hydraulic permeability of the host rock, - the self-sealing capacity,

the occurrence of earthquakes and reactivation of faults as migration paths for fluids and radionuclides.

With the World Stress Map (WSM), a database of stress orientations already exists, but for stability estimation, magnitude ratios are crucial (Figs 1\&2) Within the SpannEnD project, a comprehensive stress magnitude database was built and published for the first time (Morawietz \& Reiter, 2020).

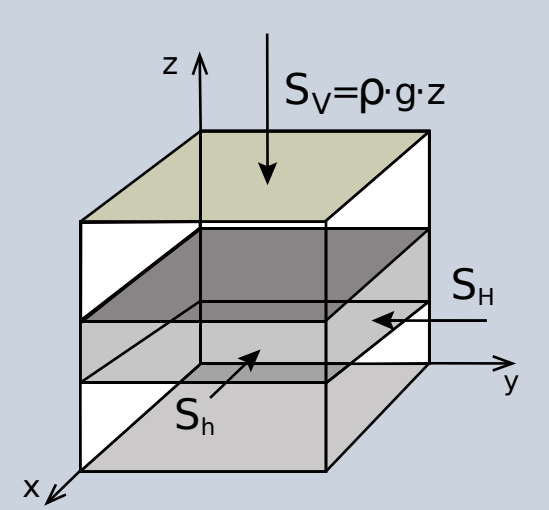

Fig. 1: Assuming that the vertical stress in the Earth's crust $S_{V}$ is a principal stress, the minimum and maximum horizontal stresses $S$ and $S_{H}$ are also principal stresses. This socalled reduced stress tensor is fully determined by four components: the $S_{H}$

$\left(\begin{array}{lll}S_{h} & 0 & 0 \\ 0 & S_{H} & 0\end{array}\right) \quad$ orientation and the magnitudes of $S_{V}, S_{H}$ $\mathrm{S}=\left(\begin{array}{lll}0 & \mathrm{~S}_{\mathrm{H}} & 0 \\ 0 & 0 & \mathrm{~S}_{\mathrm{V}}\end{array}\right) \quad$ and $\mathrm{S}_{\mathrm{h}}$
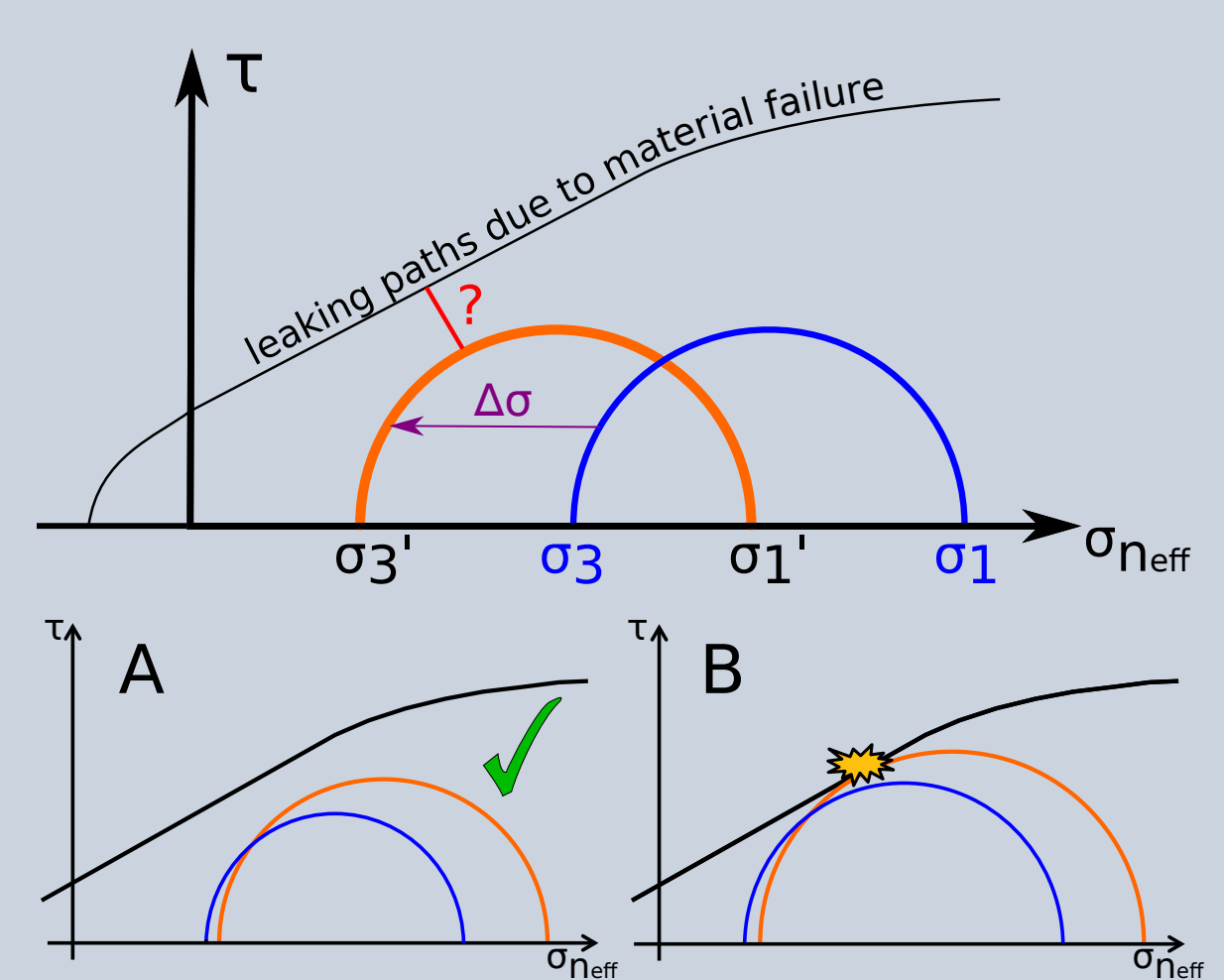

Fig. 2: Mohr's stress circle without (blue) and with (orange) influence of engineering interventions such as the construction of a deep geological repository. $\tau \equiv$ shear stress, $\sigma_{\text {neff }} \equiv$ effective normal stress. $\Delta \sigma \equiv$ influence, e.g., of free surfaces and heat development. Initial stress state (b/ue) decides whether construction remains stable $(A)$ or material failure occurs $(B)$

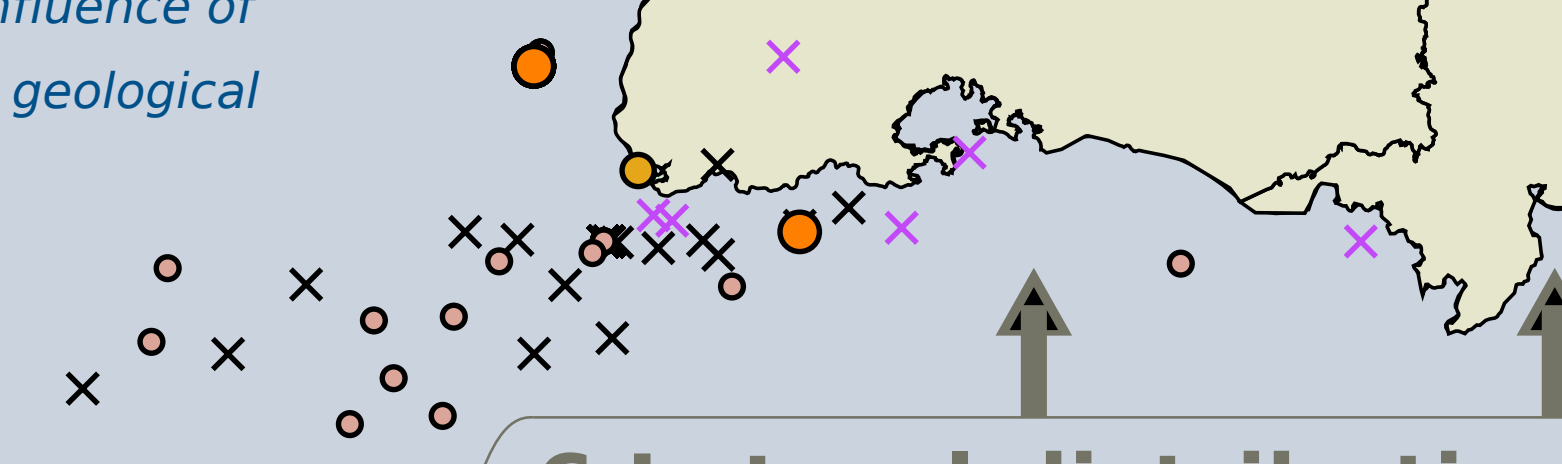

6 Lateral distribution and quality of data in the stress magnitude database
2 The role of geomechanical-numerical modeling In the comparative evaluation of potential repository sites, the estimation of the subsurface stress state is essential. However, the available point stress data are usually incomplete, since most stress indicators do not allow deriving the full 3D stress tensor. In addition, the data are distributed spatially unevenly. Therefore, a continuous and complete description of the 3D stress state can only be obtained by estimating a 3D geomechanical numerical model calibrated with available stress data. 